\title{
Attitudes towards road pricing and environmental taxation among US and UK students
}

\section{AUTHOR(S):}

Kim, Junghwa; Schmöcker, Jan-Dirk; Fujii, Satoshi; Noland, Robert B.

\section{CITATION:}

Kim, Junghwa ...[et al]. Attitudes towards road pricing and environmental taxation among US and UK students. Transportation Research Part A: Policy and Practice 2013, 48: 50-62

\section{ISSUE DATE:}

2013-02

URL:

http://hdl.handle.net/2433/172933

\section{RIGHT:}

C 2012 Elsevier Ltd.; この論文は出版社版でありません。引用の際には 出版社版をご確認ご利用ください。; This is not the published version. Please cite only the published version. 


\title{
Attitudes towards Road Pricing and Environmental Taxation among U.S. and U.K. Students
}

\author{
Junghwa Kimª, Jan-Dirk Schmöckera ${ }^{*}$, Satoshi Fujiia, Robert B. Noland ${ }^{b}$
}

\begin{abstract}
a Department of Urban Management, Kyoto University, Japan
b Edward J. Bloustein School of Planning and Public Policy, Rutgers, The State University of New Jersey, USA
\end{abstract}

* Corresponding author; E-mail: schmoecker@trans.kuciv.kyoto-u.ac.jp (Jan-Dirk Schmöcker)

Key Words: Acceptance, Road Pricing, Congestion Charge, Environmental Tax

\section{Research Highlights}

1. General environmental awareness influences acceptance of road pricing.

2. Trust in government is found to be another important determinant.

3. Determinants of acceptability of road pricing and environmental taxation are similar.

4. There are some differences in determinants of hypothetical and implemented policies.

Abstract: This study investigates the determinants of public acceptability of road pricing and environmental taxation policies. The strength and direction of causal paths between psychological determinants and the acceptability of these policies are measured with survey data from students in New Jersey, USA and London. The estimated models show that a number of well-established psychological determinants provide an explanation for the acceptability of both policies and in both locations despite various differences in the policy scenarios. Scenario fairness appears to be the most important direct determinant of acceptability in both countries. We further verify the effect of "specific trust in government" on scenario fairness and other direct determinants that indicate the important role of government performance for achieving acceptability for these measures.. Our findings further suggest that awareness of wider environmental issues, such as climate change, can lead to the support of specific sustainable transport policies, such as road pricing, which do not address climate change issues directly.

\section{Introduction}


Most transportation planners are aware that traffic causes significant environmental problems and congestion within cities and agree that pricing policies are a potential solution. There is significant concern about how the public will accept these measures, which can be seen as restricting mobility, especially for those with less income. Some people may not accept pricing policies because they believe they will be net losers. Alternatively, some people may be more willing to accept pricing policies because they believe society as a whole will gain. These perspectives influence individuals' propensity to accept and support these type of policy initiatives (Bonsall et al., 1992). Based on a survey in the U.S., Maibach et al. (2011) showed that even those who recognize the risks of climate change oppose pricing policies, such as increased gasoline taxes.

There are a number of successful urban road pricing implementations, for example in London and Stockholm, where the public supports these policies. In some other cities proposals have been rejected because of a lack of public support. For example in Edinburgh the discussion of possible economic effects of a proposed scheme raised concerns leading to its rejection in a referendum (Gaunt et al., 2007). Also a planned scheme for road pricing in New York City was rejected, largely because of a lack of public acceptability (Schaller, 2010). One of the main challenges for the implementation of road pricing is the need to design schemes that are acceptable to the public and effective in achieving their objectives (Jones, 1998). Furthermore, it is not clear how people evaluate and respond to different road pricing features and whether they perceive the benefits. Public acceptability of road pricing can often be better explained with determinants such as perceived fairness or perceived effectiveness than with utility-based concepts (Schade and Schlag, 2003). Sociodemographic status and travel behaviour also do not seem to explain acceptability; Gehlert et al (2011) found that the "life situation" of individuals explains the behavioral adaption to road pricing as well as their preferred revenue usage but not the acceptability of the scheme before its introduction. Rather, acceptance appears to be influenced mainly by psychological determinants (Gärling et al., 2008; Jakobsson et al., 2000; Ittner et al., 2003; Bartley, 1995).

Road pricing is often regarded as a tax by the population. Therefore determinants of acceptability of road pricing might be similar to determinants of acceptability of a tax. Supporting this assumption Kirchler (2007) states that acceptance of tax policy is influenced by perceived fairness, people's subjective beliefs about the complexity of the tax law, tax ethics and the evaluation of government activities. Following a recent study by Schmöcker et al. (2012) we include "trust in government" as a distal determinant of acceptability. ${ }^{1}$

Our analysis is partly based on data used in the study by Schmöcker et al. (2012). We extend this study in two ways: Whereas Schmöcker et al. discuss the acceptability of environmental taxation only, here we focus primarily on an analysis of the acceptability of road pricing, and, in addition, compare this to the acceptance of environmental taxation. Our research questions are: Firstly, do determinants for acceptability of a road pricing policy addressing city specific problems differ across countries? We use data from London

\footnotetext{
1 "Distal" describes the directness of the effect on acceptance. In Figure 1 the more to the left, the more indirect and thus the more distal the determinants of policy acceptability.
} 
and New Jersey, USA to address this question. New Jersey is situated near New York City where a proposed congestion pricing scheme was rejected. Secondly, do determinants of acceptability for road pricing differ from environmental taxation that focuses on global issues such as climate change? We address this question by comparing road pricing and environmental taxation. Thirdly, is general awareness of environmental issues a predictor for specific policies such as road pricing? We take determinants used for the environmental taxation scenarios as determinants for road pricing to investigate this question. Fourthly, do the results regarding trust in government reported in Schmöcker et al. (2012) also hold true for road pricing scenarios and the environmental taxation scenario in the New Jersey sample? Schmöcker et al argue based on a comparison between Japanese and British data that trust in government is linked to "belief in absolute values" and might be connected to religious beliefs and cultural values. In this study we therefore investigate the role of trust in government in more detail, distinguishing between specific and general trust in government.

Our samples are limited to students. In New Jersey students with varying degree levels and majors but all focusing on environmental issues participated in the survey. In London the sample was drawn from undergraduate students majoring in civil engineering. Clearly the samples are not representative for the general public. However, it is an important subgroup to investigate since some will likely pursue careers as decision makers for transport policy schemes aimed at reducing congestion or environmental externalities.

The remainder of this paper is organized as follows. The first section describes psychological determinants of public acceptability and summarizes our hypotheses. We examine the psychological determinants that are most important for the acceptability of a coercive policy in more detail. We then describe the survey method and questionnaire. In the following section, the results of the descriptive analysis of each factor are presented. The correlation of determinants of acceptability and the results of Structural Equation Model (SEM) estimations are shown in Section 4. Finally, Section 5 summarizes the findings and discusses the implications for promoting coercive (transport) policies.

\section{Review of Psychological Determinants of Public Acceptability}

There is an extensive body of literature attempting to understand general factors that influence public acceptability of pricing and taxation policies for transport. Several studies have shown that determinants relating to the scheme itself explain acceptability. For example Gärling et al. (2008) refer to the constructs infringement on freedom, fairness, problem awareness, and perceived effectiveness as psychological determinants that directly or indirectly explain policy acceptability. Eriksson et al. (2008) also demonstrated that fairness, problem awareness, and perceived effectiveness are important factors affecting acceptability (see Figure 1).

Firstly, "freedom of choice" is regarded as an important value with several connotations. In the context of road pricing it is associated with the financial burden of road pricing potentially restricting individual mobility. Some people are less willing to accept transport pricing because it infringes their 
freedom, which is perceived as unfair (Jakobsson et al., 2000). To the extent that transport pricing threatens people's individual freedom of choice, "psychological reactance" may occur.2 As a consequence, these measures may have no effect, or even opposite effects (Brehm, 1966; see also Steg, 1996; Tertoolen et al., 1998). ${ }^{3}$ Higher infringement on freedom is expected to reduce acceptability; that is the higher the charge, the higher the infringement and the lower the public acceptability (cf. Barron and Jurney, 1993; Jakobsson et al., 2000).

Secondly, a policy needs to be perceived as "fair" in order to be acceptable (Ittner et al., 2003). What is perceived as fair differs between people. In general, if people believe that the majority will benefit from a policy it is more likely to be perceived as fair and to be accepted (Schade, 2003; Jakobsson et al., 2000). The term fairness can be further divided into scenario fairness, distributional fairness and procedural fairness, all of which have a significant relationship to government policy (cf. Lind and Tyler, 1998). Scenario fairness relates to the perception of the scheme's consequences for oneself. Distributional fairness relates to the perceived fairness of the distribution of the costs and benefits within society, for example whether some population groups might be disadvantaged compared to others (Eriksson et al, 2008; Schuitema et al, 2010). Procedural fairness relates to the way the scheme was introduced, for example a scheme that was introduced without sufficient public consultation might not be acceptable.

Thirdly, the acceptability of road pricing depends on people's problem awareness (Schade \& Schlag, 2000). Any policy will be more acceptable if people are aware of current and future problems of car use and if they are convinced that policy measures to solve these problems are necessary (Steg, 2003). We distinguish three aspects of problem awareness: social problem awareness, self problem awareness and personal problem awareness. Gärling et al. (2008) found that social problem awareness is an important factor when discussing road user charging acceptability in Sweden. Schade and Schlag (2003) provide evidence that only those who are convinced that the car is a major pollutant agree that road user charging is needed. Self problem awareness relates to the awareness that "my own behavior is part of the problem" as discussed for example by Choocharukuland and Fujii (2007). Personal problem awareness describes whether a person perceives the problem to be significantly related not just to the public in general but to oneself personally (Gärling et al., 2008).

Finally, several studies have shown that the perceived effectiveness of travel demand management measures influences acceptability (e.g. Bartley, 1995). If a measure is regarded as effective, for instance for reducing traffic problems, it is more likely accepted and vice versa. A lack of perceived effectiveness is discussed as a reason for the failure of a number of proposals. Jones (1998) describes that in general participants state that they do not believe that pricing and taxation measures would solve transport-related

\footnotetext{
${ }^{2}$ Psychological reactance is defined as a response that occurs in individuals when they perceive their personal freedoms to be threatened (e.g. by a policy).They respond by increasing their opposition or seek to undermine enforcement of the policy.

${ }^{3}$ Research on acceptance of climate policy has found that sub-groups who hold individualistic values will be more opposed to policy actions as they become more educated about the consequences of climate change (Feinberg and Willer, 2011).
} 
problems such as air pollution and congestion. Taylor et al. (2010) review recent proposals for road pricing schemes in the U.S. They suggest that a clear definition of the goals, be it revenue collection or congestion reduction, and a clear case of whether this will be achieved, are keys for gaining acceptability.

Moreover, following from Fujii (2007), the aforementioned study by Schmöcker et al. (2012) proposed "trust in government" as a further determinant of acceptability. They show that trust is also an important determinant of acceptability of pricing policies in the U.K. and in Japan. ${ }^{4}$ Through correlation analysis they confirm the importance of trust in government for gaining acceptability in both countries. Path analysis shows that the effect of trust on acceptability is mediated through scheme specific determinants in both samples (Schmöcker et al., 2012). In this study, we continue this line of research by exploring whether trust in government can be distinguished as "general" and "specific" trust in line with Yamagishi and Yamagishi (1994). They define "knowledge-based trust" and "general trust" as indicators for the belief in a partner's willingness to co-operate. "Knowledge-based trust" is limited to particular objects, whereas "general trust" is a belief in the benevolence of human nature in general and thus not limited to particular objects. We apply these concepts to policy acceptability by differentiating between general trust in any kind of government and specific trust in the government that one is experiencing and hence knows to some degree. Our hypothesis is that higher levels of general trust in government is associated with higher levels of trust in specific governments.

\section{FIGURE 1}

\section{Data}

\subsection{Survey}

The New Jersey data were collected via an online survey described in Schmöcker et al (2012). An undergraduate class on Climate Change at Rutgers University in New Brunswick, New Jersey was surveyed in autumn 2009 and 2010, while a graduate class on Transportation and the Environment was surveyed in spring 2010. The London survey was conducted in November 2008. It was administered in paper to undergraduate students majoring in Civil Engineering at the end of a lecture period. We gathered a valid sample for SEM analysis of 96 students from Rutgers University and of 72 students from Imperial College,

\footnotetext{
${ }^{4}$ Schmöcker et al. (2012) characterize pricing and taxation policies as "coercive". This terminology implies that there is less choice associated with the policy. For example, to obtain mobility benefits, one has no choice but to pay, if one seeks to maintain the same behavior as prior to the policy being implemented. In essence it can be seen as infringing on freedom to engage in the previous behavior. Alternatively, many transport policies are aimed at increasing choice, such as providing carpool lanes or increased public transport service, where there is no compulsion to change one's previous behavior. Jakobsson, Fujii and Garling (2000) also implied that road pricing is regarded as coercive, "...road pricing or any other tax or fee may be perceived as a personal cost rather than as a means for improving the environment."
} 
London. The average age of respondents is similar at 20.4 years in the U.S. sample and 21.1 years in the U.K. sample. The proportion of males is $73 \%$ in the U.S. sample and $58 \%$ in the U.K. sample.

In New Jersey the course lecturer requested that the survey be administered on-line as opposed to a paper questionnaire during class as was done in London, to avoid the impression of the survey being a class requirement. In London the students may have regarded the survey as a requirement even though it was not communicated as such. Therefore, respondents in the New Jersey sample may have been more interested in the topic and may have taken more care in answering the questions. While there is no way to determine conclusively the actual impact of survey mode, our results do not suggest any major effects, other than that the New Jersey students appeared more concerned about environmental issues.

As shown in Table 1, the survey questions focused on road pricing and environmental taxation. In the first part of the survey we asked questions measuring the attitudes after providing information on a hypothetical environmental taxation scenario (see scenario description in Appendix). The second part was designed to elicit students' attitudes towards road pricing; in the New Jersey sample towards the previously rejected Manhattan congestion pricing scheme and in the London sample towards the ongoing congestion charging scheme. No specific information was given about the London charging scheme as the students surveyed were familiar with it; for the non-implemented Manhattan scheme we provided a description (see Appendix). The questions were designed to measure acceptability and its 10 psychological determinants. ${ }^{5}$ The same questions were used to measure all three forms of awareness and general government trust towards road pricing and environmental taxation. Information on car ownership and gender was also collected.

We further included questions about environmental problems such as climate change and carbon dioxide $\left(\mathrm{CO}_{2}\right)$ emissions to verify that persons associate transportwith environmental problems when they express their attitudes towards the transport policy. Specifically, we want to confirm whether the perception of environmental problems affects acceptability, the perceived effectiveness, social problem awareness, self problem awareness, and personal problem awareness. Our hypothesis is that those who are aware of climate change problems will also be more aware that car usage contributes to climate change and therefore be more likely to accept the pricing policy.

Attitude ratings were obtained on a numerical seven-point Likert scale with verbally defined mid- and endpoints (Not at all - Neutral - Yes, strongly agree). To increase reliability social problem awareness and general trust in government were measured with two and three questions, respectively. Reliability analysis showed acceptable Cronbach's alpha for acceptability of environmental tax (.89 U.S., .86 U.K.), social problem awareness (.76 U.S., .90 U.K.), and general trust in government (.91 U.S., 0.86 U.K.).

\footnotetext{
${ }^{5}$ The term acceptability is typically used for hypothetical or not yet implemented schemes whereas for implemented schemes the term acceptance is typically used (see Gärling et al, 2008 or Schuitema et al 2010). For simplicity we use the term acceptability unless we specifically refer to the London scheme or in general discuss acceptance after implementation.
} 


\section{TABLE 1}

\subsection{Summary Statistics}

We compare the mean values for acceptability and its determinants in Table 2. In the environmental taxation scenario, the U.S. sample exhibits larger mean values compared to the U.K. sample for all variables except infringement on freedom and general trust in government. The differences between the two samples are statistically significant, the means of the U.S. sample are the highest, except for distributive fairness, general and specific trust in government. For road pricing, mean values are also higher in the U.S. sample in comparison to the U.K. sample. Again infringement on freedom and general trust in government are an exception. However, the differences are only significant for the three measures of problem awareness and perceived effectiveness. The difference in perceived effectiveness suggests that students in New Jersey had higher expectations that the proposed Manhattan congestion pricing scheme would be effective for reducing global warming compared to students in London for the ongoing congestion charging scheme. This difference might be due to the sample composition. The U.S. sample consists of students attending classes focusing on environmental topics. Thus, the students may have been more interested in possible environmental impacts. As students did not answer the questionnaire at the beginning of the course, one might also hypothesize that the knowledge gained in the course increased their awareness of the possible effects of transport on climate change. Similar conclusions could be drawn regarding self problem awareness, that is New Jersey students might have understood the possible impact of their own actions better. To further understand these relationships we turn to a structural equation model (SEM) analysis in the next section.

\section{TABLE 2}

\section{Model Estimation}

\subsection{Correlation Analysis}

Simple correlations between acceptability and its proposed determinants are shown in Table 3. For the road pricing scenarios and procedural fairness, infringement on freedom, perceived effectiveness, self problem awareness and specific trust in government relate significantly to acceptability in the UK as well as the U.S. sample. In both samples scenario fairness shows the strongest correlation with acceptability. In the UK sample correlations between acceptability and social problem awareness, personal problem awareness, general trust in government and car ownership are highly significant in contrast to the U.S. sample. For the 
environmental taxation scenario the three fairness measures, infringement on freedom and self problem awareness have a statistically significant association with acceptability in both samples. Scenario fairness again has the strongest correlation with acceptability in both samples, suggesting few country-specific differences in the importance of scenario fairness.

TABLE 3

\subsection{Structural Equation Model Analysis}

We estimated structural equation models (SEMs) to verify the relations between determinants and acceptability. The results of the SEM analysis including standardized coefficients for road pricing and environmental taxation are illustrated in Figures 2 to 5 for the U.S. and U.K. sample, respectively. SEM is a multivariate regression model in which the response variable in one regression equation may appear as a predictor in another equation. In SEM, variables can be modeled to influence one another reciprocally, either directly or indirectly through other variables. The structural equations represent causal relationships (paths) among the variables in the model. The least-squares approach is a general method for the analysis of SEM with latent variables. Among several available software packages that allow SEM fitting we chose the R SEM package (Fox, 2006). A more comprehensive introduction to SEM modeling is provided in Schumacker and Lomax (2004).

Figures 2 to 5 show our model estimations. The determinants of acceptability are ordered from right to left by decreasing proximity to acceptability. Acceptability itself is placed on the far right. The models are based on the hypotheses summarized in Figure 1. We expected fairness, infringement on freedom and perceived effectiveness to relate directly to the acceptability of pricing schemes. The three aspects of problem awareness are hypothesized to have an effect on these more scheme-specific determinants and hence to influence acceptability indirectly as well as directly. Further, general trust in government is expected to be a more distal factor compared to specific trust. Car ownership might be influenced by problem awareness and is hence located in between the problem awareness and prominent factors. The models only include paths from left to right that are significant at the $5 \%$ level as well as significant correlations between determinants.

Figure 2 shows the estimated results of road pricing acceptability in the New Jersey (U.S.) sample. The model fit indices indicate a good fit with GFI=0.93, Adjusted GFI=0.90, RMSEA=0.03, and CFI=0.99 6 .

\footnotetext{
${ }^{6}$ Goodness-of-Fit-Index (GFI) may vary from 0 to 1 , but could theoretically yield meaningless negative values. By convention, GFI should be near or greater than 0.9 for an acceptable model. The model presented meets this criterion. Root Mean Square Error of Approximation (RMSEA) indicates an adequate model fit if less than or equal to 0.08 . Comparative Fit Index (CFI) is equal to the discrepancy function adjusted for sample size and ranges from 0 to 1 with a larger value indicating better model fit. Acceptable model fit is indicated by a CFI value of 0.9 or larger.
} 
The signs of the significant paths are in accordance with our hypotheses. Acceptability is influenced directly by all three fairness aspects and perceived effectiveness, which in turn is influenced by gender. Females have a lower perception that the road pricing policy would be effective indicated by an indirect path between gender and acceptability. The model also shows that infringement on freedom does not affect acceptability directly nor does general trust in governments or car ownership. Self problem awareness affects acceptability only indirectly.

\section{FIGURE 2}

The model for the London (U.K.) sample for road pricing is shown in Figure 3. Model fit indices are somewhat lower than for the New Jersey (U.S.) sample, but still acceptable with GFI=0.89, Adjusted $G F I=0.82$, RMSEA $=0.11$, and $C F I=0.91$. This model shows the same relationships between specific trust in government and determinants of acceptability such as the fairness aspects, infringement on freedom, and perceived effectiveness compared to the New Jersey (U.S.) sample. In contrast we find that car ownership has a direct and indirect (via scenario fairness) effect on acceptability. Furthermore infringement influences accessibility and scenario fairness has a stronger effect on acceptability, whereas procedural fairness, distributional fairness and perceived effectiveness do not influence acceptability significantly. In addition we find that specific trust in governments directly influences acceptability and that general trust affects specific trust.

FIGURE3

Figures 4 and 5 illustrate the models for the environmental tax scenario. We omit gender and car ownership in both models as we do not find any significant paths. For the U.S. sample we identify a good model fit with $\mathrm{GFI}=0.93$, Adjusted $\mathrm{GFI}=0.86$, RMSEA $=0.08$, and $\mathrm{CFI}=0.95$ (Figure 4). Again specific trust plays a central role. In contrast to Figure 2, there is a significant path from infringement on freedom to acceptability. Acceptability appears to depend on more factors as we also find direct paths from general and specific trust to acceptability. As in Figures 2 and 3, personal awareness affects infringement on freedom and we also find that social problem awareness indirectly affects acceptability via perceived effectiveness.

FIGURE 4 
Figure 5 describes the environmental taxation model for the U.K. sample. In contrast to the U.S. sample, but in parallel to the two road pricing scenarios, we also find a lower, though still acceptable model fit with GFI=0.91, Adjusted GFI=0.85, RMSEA $=0.08$, and $\mathrm{CFI}=0.94$. Two relations stand out in this model: General trust in government negatively effects infringement on freedom and social problem awareness directly influences acceptability.

\section{FIGURE 5}

Table 4 summarizes the explained variance $\left(R^{2}\right)$ of the four models. Their total effects are shown in Table 5. Acceptability in the U.K. road pricing model exhibits the highest $\mathrm{R}^{2}$ with .53 . For the other three models the $\mathrm{R}^{2}$ for acceptability is around .30 . We find similar patterns of results for the proximal determinants of acceptability in the road pricing model as well as the environmental tax scenario models. This indicates a rather stable relationship between well-established psychological determinants and acceptability. Furthermore, we find that the path coefficients are more constant across countries when the environmental tax scenario is considered compared to road pricing. The level of significance for these paths differ, depending on local scheme specifics such as the differences in the London and the proposed Manhattan road pricing scheme.

TABLE 4

\subsection{Discussion}

In this section we discuss the similarities and differences between the role of the determinants. Following our hypotheses summarised in Figure 1 regarding the role of trust in government and environmental problem awareness, we discuss in particular problem awareness and trust in government since they have not been explored in the literature so far.

\subsubsection{Fairness, infringement on freedom and perceived effectiveness}

Scenario fairness has the strongest direct effect on acceptability in all four models. In the U.S. sample, the relevance of fairness is further highlighted as all three aspects of fairness (scenario, distributive, 
and procedural) are statistically significant, while in the U.K. sample only scenario fairness is statistically significant. This might be due to the more recent discussion of congestion pricing in New York City compared to London. U.K. participants may not remember the implementation process of the congestion charging scheme that well. We have to consider that we surveyed students with an average age of 21 years who thus were young teenagers during the introduction of congestion charging in London and may have even lived elsewhere in the U.K. at that time.

We find infringement of freedom to be of more importance in the U.K and in particular for road pricing. This might be due to the fact that Londoners do indeed experience congestion charging, while for U.S. students the pricing scheme remained a hypothetical scenario. Our results on perceived infringement of freedom for the hypothetical environmental tax support this interpretation, as in both countries the coefficients are much lower than for infringement of freedom for road pricing in London (Table 5).

Perceived effectiveness has a direct effect on acceptability in three out of the four models. It is not statistically significant in the U.K. road pricing model. We emphasize that perceived effectiveness is related to global warming in our study (see wording of question in Table 1.) Obviously the main perceived effect of road pricing might not be $\mathrm{CO}_{2}$ emission reductions but congestion reductions and other improvements in traffic conditions. However, for the U.S. sample we find effectiveness to reduce global warming is an important determinant. One explanation for this might be our sample composition with U.S. students likely being more focused on global warming issues. Another equally valid interpretation might be similar to the above explanation regarding infringement of freedom. In the U.S., the scheme remained hypothetical whereas in London the scheme affecting traffic is immediate and visible. Thus, U.K. student may relate effectiveness only to traffic conditions. In the U.S., transport effects may not be so dominant in participants' mind so that environmental effects are considered equally.

\subsubsection{Problem Awareness}

In line with our hypothesis for road pricing, perceived effectiveness is significantly influenced by self problem awareness in the U.K. sample. Those who understand that their own behaviour is part of the problem are more likely to understand that effective policies need to be introduced to solve the problem. In the U.S. sample social problem awareness has a direct effect on perceived effectiveness and an indirect effect on acceptability in both scenarios. Social problem awareness influences acceptability in both samples, though the coefficients are fairly low. This is particularly noteworthy as our measures for problem awareness and perceived effectiveness are less directly related to the scheme. Previous studies on acceptability of road pricing consider awareness of congestion problems and perceived effectiveness to solve congestion problems whereas we ask about problem awareness and perceived effectiveness regarding "global warming". Personal problem awareness shows significant paths in the U.S. sample whereas self problem awareness is not significantly associated with acceptability in any country (see Table 5). This possibly 
suggests that the importance that individual life style decisions have on environmental problems is not sufficiently appreciated by the respondents in our samples.

\subsubsection{Trust in Government}

Figures 2 to 5 illustrate the central role of specific trust in government with significant paths to all proximal determinants of acceptability in both samples and policy scenarios. For both scenarios specific trust in government significantly affects all three forms of fairness, as well as infringement on freedom and perceived effectiveness in both samples with the expected sign.

The results in Table 5 confirm the importance of specific government trust and scenario fairness in both policies and both samples. This result is noteworthy as it was obtained despite the differences in the samples, their locations, and the details of the coercive policies. The path based on specific trust in government $->$ scenario fairness $->$ acceptability is significant in all models; thus we use $t$-tests to understand whether there are significant differences in the path determinants (see Table 6). Interestingly we find that the differences in coefficients are statistically significant for the road pricing scenario addressing local problems but not for the environmental tax scenarios addressing global warming. This result as well as the result of the path analysis suggests that the path from trust $->$ fairness $\rightarrow$ acceptability is significant for the policies in general. This is in line with Kirchler (2007) and extends the results of previous studies on road pricing.

\section{TABLE 6}

Our results regarding the influence of general trust in government are less clear. Whereas significant paths can be found in the two U.K. models, in the U.S. sample we find significant relations only for the environmental tax scenario. In the U.K. the national government exercises substantial control over transport policy, although London has substantial autonomy. In the U.S. there are more distinct and varied levels of government (i.e., federal versus state, as well as more autonomous local governments) meaning that a correlation between general trust and trust in a specific government is more difficult to define. Furthermore, the fact that we asked for trust in a past government that proposed a policy that was not implemented might be another reason for the lack of statistical significance. In London the government has also changed since the introduction of road pricing, but at least the effects can still be observed and experience of respondents might still relate the effects to the current government. All of this might contribute to the fact that the London respondents associate government in general more with the government that implemented road pricing. ${ }^{7}$

\footnotetext{
7 Another possible distinction between the U.S. and U.K. samples is in the understanding of the term "government". In the U.K., this is strongly associated with the party in power that is running the government. In the U.S., the term "government" is more strongly associated with the structure of power which is designed to balance various party's that might control different elements of that structure, and thus the term may have a different connotation.
} 
An alternative might be that general trust is more important for less tangible problems such as climate change. For daily problems such as congestion, it seems reasonable to assume that the immediate performance of governments is more important whereas for the acceptability of more abstract, long term problems general attitudes might be more important.

\subsubsection{Sociodemographics: Car ownership and gender}

For sociodemographic variables we found that car ownership is significant in the U.K. but not in the U.S. sample where $61.3 \%$ owned a car. Due to a higher car dependency in the U.S., there may be little attitudinal difference between car owners and non-car owners in this sample of students. U.K. car owners $(52.8 \%)$ assess road pricing as less fair and trust less in the London government, possibly reflecting the importance of the congestion pricing scheme as a political topic within London over the last few years. The negative effect of gender on specific trust in government (U.K. sample) and perceived effectiveness (U.S. sample) indicates that it is more difficult to gain acceptability for road pricing from women compared to men in both countries. We further find that personal problem awareness affects car ownership in the U.K. sample. However, we cannot verify this with the U.S. sample, thus, we do not emphasise this result but leave it as a topic for further research.

\section{Conclusions}

Our results highlight the similarity of determinants of acceptability for both road pricing and environmental taxation but also that some reasonable differences exist. Gaining acceptability for road pricing is difficult and depends on the specifications of the proposed scheme. This is confirmed by our analysis that emphasizes the importance of determinants such as perceived fairness (distributive, procedural, and scenario), perceived infringement of freedom and perceived effectiveness. In addition to these schemespecific factors there are a number of more general or distal factors that determine acceptability. We show that perceived effectiveness and problem awareness might not necessarily have to be determined by scheme-specific aspects but can also relate to a more general awareness of environmental issues. Previous studies considered primarily congestion-reducing effects for measuring perceived effectiveness whereas we asked participants whether they perceive road pricing to be effective at reducing global warming.

Furthermore we can state that the most influential factor in all locations for both the investigated policies is scenario fairness. Fairness in turn is influenced the most by specific trust in government in both samples and for both policies, despite important differences between the schemes. Therefore, regardless of the sample, we conclude that those who trust the government that implements the pricing or taxation policy tend to perceive the scheme as fair, and those who perceive it as fair tend to accept it. The results of our analysis therefore highlight that the public's trust in its government (and those running the government) is crucial for obtaining acceptability. The results are quite stable across the two countries for both policies. How this trust is gained will depend in turn on a number of factors. In particular our U.K. sample results suggest 
that gaining trust occurs partly through a general belief that governments should be obeyed. According to Schmöcker et al (2012) such a general trust might be encouraged by aiming to uphold values that avoid beliefs that all judgments are up to a public's own preferences. Since the path for specific trust toward government $\rightarrow$ scenario fairness $\rightarrow$ acceptability is of such importance we suggest that providing information about the policy's effect on the wider population is an effective strategy.

We believe that our study results have some important implications. Decision makers should consider the importance of attitudes in the general population and trust in institutions when aiming to introduce pricing or taxation policies. Even if the scheme specifics have been carefully determined and analyzed, a scheme might not gain much support if citizens do not trust their government or are not aware of wider environmental and societal problems. Effective public consultation and communication strategies are probably needed to both educate the public, but also to formulate policies that take their concerns into account.

Drawing further firm conclusions from our study is partly hindered by the different sample compositions. In the U.K. civil engineering students were surveyed while in the U.S. there was a mix of different disciplinary backgrounds. As our analysis indicated that the role of social problem awareness is important in the U.S. sample, we tentatively suggest that there is an influence of interest and/or knowledge about "climate change" on student attitudes toward environmental problems and transport policy. This could be confirmed with further research and a more diverse sampling strategy. Furthermore, as discussed, some differences in acceptability and acceptance of the road pricing schemes might be because the Manhattan scheme was hypothetical and never implemented.

Schuitema et al. (2010) found that acceptance of the congestion charge in Stockholm was higher shortly after its implementation than its acceptability shortly beforehand. Such a comparison is not possible with our data set, but our results suggest that the long-term determinants of acceptability might need further investigation as the public will not recall the situation before implementation several years after a scheme is active. In a similar vein further research should examine whether there is a correlation between level of acceptability and reductions in car usage. First results suggest that there might be only a weak relationship between acceptability and car use reduction (Gehlert et al, 2008; Cools et al, 2011). However the relation between car use reduction and acceptability determinants still warrants further investigation.

Surveying engineering students gave us an understanding of the attitudes of those who may be future analysts and decision makers on the implementation of transport pricing schemes, although we recognize the limitations of using such a sample. In future work the survey should be extended to the general population. Other distal determinants that might have significant effects on acceptability, for example, personality determinants such as "arrogance" and "autistic tendency" should also be considered. Hatori and Fuji (2008) propose a measure of these factors that can explain a person's willingness to cooperate with others. We also expect distal determinants to explain a person`s political bias, for instance "utilitarian" 
and "libertarianism". That in turn could affect public acceptability towards transport pricing policies, in particular if proposed by a government close to one's political preference (Hårsman and Quigley, 2010).

\section{References}

Baron, J. and Jurney, J. (1993) Norm against voting for coerced reform. Journal of Personality and Social Psychology, 64, 347-355.

Bartley, B. (1995) Mobility impacts, reactions and options, traffic demand management options in Europe: the MIRO project. Traffic Engineering and Control, 36, 596-603.

Brehm, J. W. (1966) A theory of psychological reactance. Academic Press, New York.

Bonsall, P. and Wardmanm, M. and Nash C. and Hopkinson P. (1992) Development of a survey instrument to measure subjective valuations of non-use benefits of local public transport services. Selected Reading in Transport Survey Methodology eds A.J. Richardson and A.H. Meyburg, Eucalyptus Press, AUS.

Choocharukuland, K. and Fujii, S. (2007) Psychological Factors Influencing Behavioral Intention of Private Car Use in Future Work Trip. Journal of the Eastern Society for Transportation Studies, 7, 211-222.

Cools, M. and Brijs, K. and Tormans, H. and Moons, E. and Janssens, D., Wets, G. (2011) The sociocognitive links between road pricing acceptability and changes in travel-behaviour. Transportation Research Part A: Policy and Practice, 45(8), 779-788.

Duff, A. and Cotgrove, S. (1982) Social Value and the Choice of Careers in Industry. Journal of Occupational Psychology, 55, 97-107.

Eriksson, L. and Garvill, J. and Nordlund A.M. (2008) Acceptability of single and combined transport policy measures: The importance of environmental and policy specific beliefs. Transportation Research Part A: Policy and Practice, 42, 1117-1128.

Feinberg, M. and Willer, R. (2011) Apocalypse Soon? Dire Messages Reduce Belief in Global Warming by Contradicting Just-World Beliefs. Psychological Science, 22(1), 34-38.

Fox, J. (2006) Teacher's Corner: Structural Equation Modeling With the sem Package in R. Structural Equation Modeling: A Multidisciplinary Journal, 13(3), 465-486.

Fujii, S. and Gärling, T. and Jakobsson, C. and Jou, R.C. (2004) A cross-country study of fairness and infringement on freedom as determinants of car owners' acceptance of road pricing. Transportation, $31,285-295$.

Gehlert, T. and Kramer, C. and Nielsen, O.A. and Schlag, B. (2011) Socioeconomic differences in public acceptability and car use adaptation towards urban road pricing. Transport Policy, 18(5), 685-694 
Gehlert, T. and Nielsen, O.A. and Rich, J. and Schlag, B. (2008) Public acceptability change of urban road pricing schemes. Proceedings of the Institution of Civil Engineers, Transport, 161, 111-121.

Gärling, T. and Jakobsson, C. and Loukopoulos, P. and Fujii, S. (2008) Acceptability of road pricing. Pricing in road transport: Multidisciplinary perspectives eds E. Verhoef and E. Bliemer and L. Steg and Wee B. Van, Edward Elgar, Cheltenham.

Gaunt, M. and Rye, T. and Allen, T. (2007) Public Acceptability of Road Pricing: The Case of Edinburgh and the 2005 Referendum. Transport Reviews, 27(1), 85-102.

Hårsman, B. and Quigley, J.M. (2010) Political and public acceptability of congestion pricing: Ideology and self-interest. Journal of Policy Analysis and Management, 29(4), 854-874.

Hatori, T. and Fujii, S. (2008) The Mass Man as Defector : Implications of Ortega's "the rebellion of the Masses" on Social Dilemma Research. The 29th International Congress of Psychology, 4(3), 431.

Jakobsson, C. and Fujii, S. and Gärling, T. (2000) Determinants of private car users' acceptability of road pricing. Transport Policy, 7, 133-158.

Jones, P.M. (1998) Urban road pricing: public acceptability and barriers to implementation. Road Pricing, Traffic Congestion and the Environment, Issue of Efficiency and Social Feasibility eds K.J. Button and E.T. Verhoef, pp.263-284, Edward Elgar, Cheltenham.

Kirchler, E. (2007) The Economic Psychology of Tax Behaviour. Cambridge University Press, Cambridge.

Ittner, H. and Becker, R. and Kals, E. (2003) Willingness to support traffic policy measures: The role of justice. Acceptability of transport pricing strategies eds J. Schade and B. Schlag, Elsevier, Oxford.

Lin, E.A. and Tyler, T.R. (1998) The Social Psychology of Procedural Justice. Plenum Press, New York.

Maibach, E.W. and Leiserowitz, A. and Connie, R-R. and Mertz, C.K. (2011) Identifying Like-Minded Audiences for Global Warming Public Engagement Campaigns: An Audience Segmentation Analysis and Tool Development, PLOS ONE, 6(3), 1-9.

Offe, C. (1999) How can we trust our fellow citizens?. Demoncracy and Trust eds M.E. Warren, pp. 42-87, Cambridge University Press, Cambridge.

Quddus, M-A. and Bell, MGH. and Schmöcker, J-D. (2007) The impact of the congestion charge on the retail business in London: An econometric analysis. Transport Policy, 14, 433-444.

Schade, J. and Schlag, B. (2003) Acceptability of Transport Pricing Strategies. Elsevier, Oxford.

Schade, J. (2003) European research results on transport pricing acceptability. Acceptability of transport pricing strategies eds J. Schade and B. Schlag, Elsevier, Oxford.

Schade, J. and Schlag, B. (2000) Public acceptability of traffic demand management in Europe. Traffic Engineering and Control, 41(8), 314-318.

Schaller, B. (2010) New York's Congestion Pricing Experience and Implications for Road Pricing Acceptance in the United States. Paper presented at the 89th Annual Meeting of the Transportation Research Board, Washington D.C., January 2010. 
Schmöcker, J-D. and Pettersson, P. and Fujii, S. (2012) Comparative Analysis of Proximal and Distal Determinants for the Acceptance of Coercive Charging Policies in the U.K. and Japan. International Journal of Sustainable Transportation, 6(3), 156-173.

Schmöcker, J-D. and Frozon, A. and Quddus, M-A. and Bell, MGH. (2006) Changes in the frequency of shopping trips in response to congestion charge. Transport Policy, 13 (3), 217-228.

Schuitema, G. and Steg, L. and Forward, S. (2010) Explaining differences in acceptability before and acceptance after the implementation of a congestion charge in Stockholm. Transportation Research Part A: Policy and Practice, 44, 99-109.

Schumacker, R.E. and Lomax, R.G., 2004. A Beginner's Guide to Structural Equation Modelling: 2nd Edition. Psychological Press, Taylor \& Francis, Mahwah, NJ: Lawrence Erlbaum.

Steg, E.M. (1996) Behaviour Change for Reducing the Use of Motor-Cars. Theoretical Analysis and Empirical Study on Problem Awareness, Willingness-to-Change and Evaluation of Policy Measures, Ph.D. Thesis, University of Groningen, The Netherlands.

Steg, L. (2003) Factors influencing the acceptability and effectiveness of transport pricing. Acceptability of transport pricing strategies eds Schade, J. and Schlag, B., Elsevier, Oxford.

Steg, L. and Vlek, C. (1997) The Role of Problem Awareness in Willingness-to-Change Car Use and in Evaluating Relevant Policy Measures. Traffic and Transportation Psychology: Theory and Application eds T. Rothengatter and E.C. VAYA, pp.465-475, Elsevier, Oxford.

Tertoolen, G. and Kreveld, D.V. and Verstraten, E.C.H. (1998) Psychological resistance against attempts to reduce private car use, Transport Policy, 7, 243-257.

Taylor, B.D. and Iseki, H. and Kalauskas, R. (2010) Addressing equity issues in political debated over road pricing. Paper presented at the $89^{\text {th }}$ annual Meeting of the Transportation Research Board, Washington D.C., January 2010.

Yamagishi, T. and Yamagishi, M. (1994) Trust and commitment in the United States and Japan, Motivation and Emotion, 18(2), 129-166. 


\section{Appendix}

Hypothetical Environmental Taxation Scenario for U.K.

The U.K. government has decided to introduce an environmental tax of $£ 50$ per month to be paid by all U.K. residents including all university students.

The decision was made after a long debate with several economists and scientists through which the government got convinced that this additional tax is needed to influence greenhouse emission. The tax will be used for environmental research and to subsidise the introduction of new technology that emits less $\mathrm{CO} 2$. The government accounted that they justified the amount by scientific research referring to the carbon footprints.

Information given about Manhattan Road pricing Proposal

In 2007, New York City Mayor Bloomberg proposed that a congestion charge be levied on traffic in Manhattan. This would have priced traffic south of $60^{\text {th }}$ Street, with exemptions for some through routes. Drivers using toll crossings to enter Manhattan would have paid only the difference between their toll and the congestion charge. The charge would apply on weekdays from 6:00 a.m. to 6:00 p.m. The proposed fees would be $\$ 8$ for cars and commercial vehicles and $\$ 21$ for trucks entering from outside the zone. Transit buses, emergency vehicles, taxis and for-hire vehicles, and vehicles with handicapped license plates would not be charged the fee. Taxi and livery trips that begin, end or touch the zone would have a $\$ 1$ surcharge. Vehicles would be charged only once per day. Charges would have been collected electronically, for example through EZ Pass or license plate cameras. Revenue from the congestion charge would have contributed to accelerating capital investments in public transit. 
Table 1. Questions used to measure the determinants

\begin{tabular}{|c|c|c|c|}
\hline \multirow{2}{*}{\multicolumn{2}{|c|}{ Variables }} & \multicolumn{2}{|l|}{ Questions } \\
\hline & & Road Pricing & Environmental Taxation \\
\hline \multirow{2}{*}{\multicolumn{2}{|c|}{ Acceptability }} & \multirow{2}{*}{ Do you support the congestion charge? } & $\begin{array}{l}\text { Do you support this government decision to implement an } \\
\text { environmental tax? }\end{array}$ \\
\hline & & & $\begin{array}{l}\text { Are you willing to accept this government's decision to implement } \\
\text { an environmental tax? }\end{array}$ \\
\hline \multirow{9}{*}{$\begin{array}{l}\text { Proximal } \\
\text { Determinants }\end{array}$} & Scenario Fairness & Do you think the congestion charge is fair? & Do you think this environmental tax fair? \\
\hline & Procedural Fairness & $\begin{array}{l}\text { Do you think the process how congestion charge was introduced } \\
\text { is fair? }\end{array}$ & $\begin{array}{l}\text { Do you think the process of government decision making that lead } \\
\text { to an environmental tax is fair? }\end{array}$ \\
\hline & Distributive Fairness & Do you think the congestion charge is impartial? & Do you think this environmental tax is equitable? \\
\hline & $\begin{array}{l}\text { Infringement on } \\
\text { Freedom }\end{array}$ & Do you think the congestion charge "infringes on your freedom"? & Do you think environmental tax "infringes on your freedom"? \\
\hline & $\begin{array}{l}\text { Perceived } \\
\text { Effectiveness }\end{array}$ & $\begin{array}{l}\text { Do you think the congestion charge helps to eventually reduce } \\
\text { the effect of global warming? }\end{array}$ & $\begin{array}{l}\text { Do you think a tax like this can help to eventually reduce the effect } \\
\text { of global warming? }\end{array}$ \\
\hline & Social Problem & \multicolumn{2}{|l|}{ How serious do you believe the problem of climate change is? } \\
\hline & Awareness & \multicolumn{2}{|l|}{ Do you think climate change will seriously damage our society? } \\
\hline & $\begin{array}{l}\text { Self Problem } \\
\text { Awareness }\end{array}$ & \multicolumn{2}{|c|}{ Do you think the $\mathrm{CO}_{2}$ that you produce in your daily life will contribute to climate change and this will negatively influence society? } \\
\hline & $\begin{array}{l}\text { Personal Problem } \\
\text { Awareness }\end{array}$ & \multicolumn{2}{|l|}{ Do you think global warming will serious damage yourself? } \\
\hline \multirow{3}{*}{$\begin{array}{l}\text { Distal } \\
\text { Determinants }\end{array}$} & General Trust in & \multicolumn{2}{|l|}{ I respect the government. } \\
\hline & Government & \multicolumn{2}{|l|}{ In general I trust the government. } \\
\hline & $\begin{array}{l}\text { Specific Trust in } \\
\text { Government }\end{array}$ & $\begin{array}{l}\text { Do you trust the government that made the decision to introduce } \\
\text { the congestion charge? }\end{array}$ & $\begin{array}{l}\text { Do you trust the federal government to make a decision to } \\
\text { introduce this tax? }\end{array}$ \\
\hline \multirow{2}{*}{$\begin{array}{l}\text { Sociodemogra } \\
\text { phic } \\
\text { information }\end{array}$} & Car ownership & \multicolumn{2}{|l|}{ Do you own a car? Yes/No } \\
\hline & Gender & \multicolumn{2}{|l|}{ Please mark your gender. Male/Female } \\
\hline
\end{tabular}


Table 2. Means and standard deviations of acceptability and its determinants

\begin{tabular}{|c|c|c|c|c|c|c|}
\hline \multirow{3}{*}{ Determinants } & \multicolumn{3}{|c|}{ Road Pricing } & \multicolumn{3}{|c|}{ Environmental Taxation } \\
\hline & \multicolumn{2}{|c|}{ Mean (Std.dev.) } & \multirow{2}{*}{ t-test } & \multicolumn{2}{|c|}{ Mean (Std.dev.) } & \multirow{2}{*}{ t-test } \\
\hline & U.S. & U.K. & & U.S. & U.K. & \\
\hline Acceptance & $4.92(1.81)$ & $4.46(2.14)$ & -1.49 & $3.73(1.88)$ & $3.06(1.75)$ & $-2.37^{*}$ \\
\hline Scenario Fairness & $4.40(1.84)$ & $4.08(2.10)$ & -1.02 & $3.30(1.84)$ & $2.68(1.73)$ & $-2.23^{*}$ \\
\hline Procedural Fairness & $4.26(1.56)$ & $3.93(1.91)$ & -1.23 & $3.85(1.68)$ & $3.04(1.65)$ & $-3.13^{* *}$ \\
\hline Distributive Fairness & $4.41(1.60)$ & $3.97(1.59)$ & -1.76 & $3.58(3.58)$ & $3.57(4.63)$ & -0.05 \\
\hline Infringement on Freedom & $3.40(1.76)$ & $3.74(2.14)$ & 1.13 & $3.23(3.23)$ & $3.90(1.81)$ & $2.44^{*}$ \\
\hline Perceived Effectiveness (Climate) & $4.62(1.67)$ & $3.22(1.92)$ & $-5.01^{* *}$ & $4.47(4.47)$ & $3.32(1.80)$ & $-4.27^{* *}$ \\
\hline Social Problem Awareness (Climate) & $6.14(0.98)$ & $5.32(1.54)$ & $-4.18^{* *}$ & $6.14(0.98)$ & $5.32(1.54)$ & -4.18 \\
\hline Self Problem Awareness (Climate) & $5.61(1.04)$ & $4.37(1.74)$ & $-5.72^{* *}$ & $5.61(1.04)$ & $4.37(1.74)$ & $-5.72^{\star *}$ \\
\hline Personal Problem Awareness (Climate) & $4.95(1.62)$ & $3.57(1.86)$ & $-5.13^{\star *}$ & $4.95(1.62)$ & $3.57(1.86)$ & $-5.13^{\star \star}$ \\
\hline General Trust in Government & $4.03(1.54)$ & $4.23(1.26)$ & 0.89 & $4.03(1.54)$ & $4.23(1.26)$ & 0.89 \\
\hline Specific Trust in Government & $4.11(1.53)$ & $3.92(1.64)$ & -0.80 & $3.38(3.38)$ & $3.22(1.43)$ & -0.67 \\
\hline
\end{tabular}


Table 3. Correlations between acceptability and its determinants

$\left({ }^{* *}\right.$ : significant on $1 \%$ level, * : significant on $5 \%$ level)

\begin{tabular}{|c|c|c|c|c|}
\hline \multirow{2}{*}{ Determinants } & \multicolumn{2}{|c|}{ Road Pricing } & \multicolumn{2}{|c|}{ Environmental Taxation } \\
\hline & U.S. & U.K. & U.S. & U.K. \\
\hline Scenario Fairness & $0.82^{* *}$ & $0.91^{\star *}$ & $0.70^{* *}$ & $0.73^{\star *}$ \\
\hline Procedural Fairness & $0.77^{\star \star}$ & $0.80^{\star *}$ & $0.59^{* *}$ & $0.66^{* *}$ \\
\hline Distributive Fairness & $0.67^{* *}$ & $0.42^{* *}$ & $0.58^{* *}$ & $0.28^{*}$ \\
\hline Infringement on Freedom & $-0.41^{* *}$ & $-0.74^{* \star}$ & $-0.44^{* *}$ & $-0.45^{\star *}$ \\
\hline Perceived Effectiveness (Climate) & $0.51^{* *}$ & $0.56^{* *}$ & 0.43 & $0.69^{* *}$ \\
\hline Social Problem Awareness (Climate) & 0.11 & $0.25^{\star}$ & $0.32^{\star *}$ & $0.38^{* *}$ \\
\hline Self Problem Awareness (Climate) & $0.27^{\star *}$ & $0.36^{* *}$ & $0.23^{*}$ & 0.04 \\
\hline Personal Problem Awareness (Climate) & 0.20 & $0.37^{\star \star}$ & 0.04 & 0.16 \\
\hline General Trust in Government & 0.07 & $0.2^{*}$ & $0.28^{* *}$ & 0.14 \\
\hline Specific Trust in Government & $0.66^{* *}$ & $0.63^{* *}$ & $0.59^{* *}$ & 0.51 \\
\hline Car ownership & 0.10 & $-0.42^{* *}$ & - & - \\
\hline Gender & -0.19 & -0.16 & - & - \\
\hline
\end{tabular}

Table 4. Explained variance $\left(R^{2}\right)$

\begin{tabular}{l|l|l|l|l}
\hline \multirow{2}{*}{ Determinants } & Road Pricing & \multicolumn{2}{l}{ Environmental Taxation } \\
\cline { 2 - 5 } & U.S. & U.K. & U.S. & U.K. \\
\hline Acceptance & 0.32 & 0.53 & 0.29 & 0.29 \\
\hline Scenario Fairness & 0.49 & 0.21 & 0.15 & 0.18 \\
\hline Procedural Fairness & 0.48 & 0.49 & 0.18 & 0.37 \\
\hline Distributive Fairness & 0.18 & 0.29 & 0.07 & 0.15 \\
\hline Infringement on Freedom & 0.21 & 0.31 & 0.05 & 0.10 \\
\hline Perceived Effectiveness & 0.18 & 0.21 & 0.07 & 0.19 \\
\hline Specific Trust in Government & - & 0.37 & 0.10 & 0.13 \\
\hline Car Ownership & - & 0.02 & - & - \\
\hline
\end{tabular}


Table 5. Total effects (Indirect effects) of determinants on acceptability

\begin{tabular}{l|l|l|l|l}
\hline \multirow{2}{*}{ Determinants } & \multicolumn{2}{l}{ Road Pricing } & \multicolumn{2}{l}{ Environmental Taxation } \\
\cline { 2 - 5 } & U.S. & U.K. & U.S. & U.K. \\
\hline Scenario Fairness & $0.40(0.00)$ & $0.69(0.00)$ & $0.37(0.00)$ & $0.34(0.00)$ \\
\hline Procedural Fairness & $0.29(0.00)$ & - & $0.18(0.00)$ & $0.25(0.00)$ \\
\hline Distributive Fairness & $0.19(0.00)$ & - & - & - \\
\hline Infringement on Freedom & - & $-0.40(-0.21)$ & $-0.16(0.00)$ & $-0.14(0.00)$ \\
\hline Perceived Effectiveness & $0.21(0.00)$ & - & $0.11(0.00)$ & $0.27(0.00)$ \\
\hline Social Problem Awareness & $0.05(0.05)$ & - & $0.02(0.02)$ & $0.12(0.00)$ \\
\hline Self Problem Awareness & - & - & - & - \\
\hline Personal Problem Awareness & $0.08(0.08)$ & $0.16(0.16)$ & $0.03(0.03)$ & - \\
\hline General Trust in Government & - & $0.29(0.29)$ & $0.27(0.17)$ & $0.20(0.20)$ \\
\hline Specific Trust in Government & $0.60(0.60)$ & $0.57(0.49)$ & $0.56(0.28)$ & $0.46(0.46)$ \\
\hline Car Ownership & - & $-0.32(-0.21)$ & & \\
\hline Gender & $-0.05(-0.05)$ & $-0.15(-0.15)$ & & \\
\hline
\end{tabular}

Table 6. t-tests of differences between estimated path coefficients

${ }^{* *}$ : significant on $1 \%$ level, *: significant on $5 \%$ level)

\begin{tabular}{l|l|l}
\hline \multirow{2}{*}{ Path } & Road Pricing & Environmental Taxation \\
\cline { 2 - 3 } & t-value & t-value \\
\cline { 2 - 3 } & U.S. vs. U.K. & U.S. vs. U.K. \\
\hline Specific Trust in Government $\rightarrow$ Scenario Fairness & $2.86^{* *}$ & 0.45 \\
\hline Scenario Fairness $\rightarrow$ Acceptance & $3.40^{* *}$ & 0.30 \\
\hline
\end{tabular}




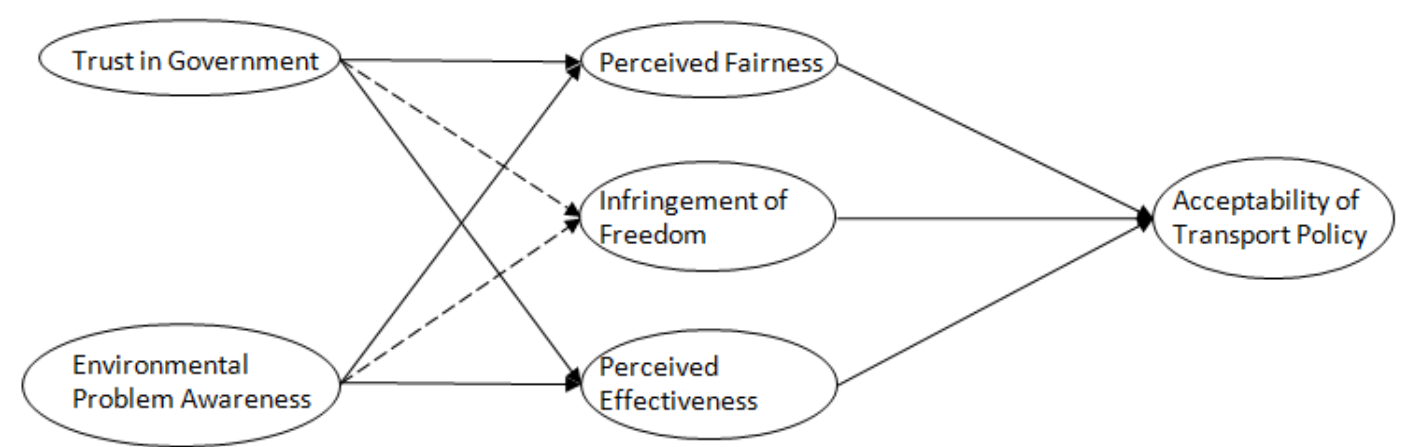

Figure 1. Hypothetical modeling framework

(Ellipses: Latent variables; Thick left-to-right arrows: paths significant within the $5 \%$ level; Dotted arrows: negative path and correlation) 


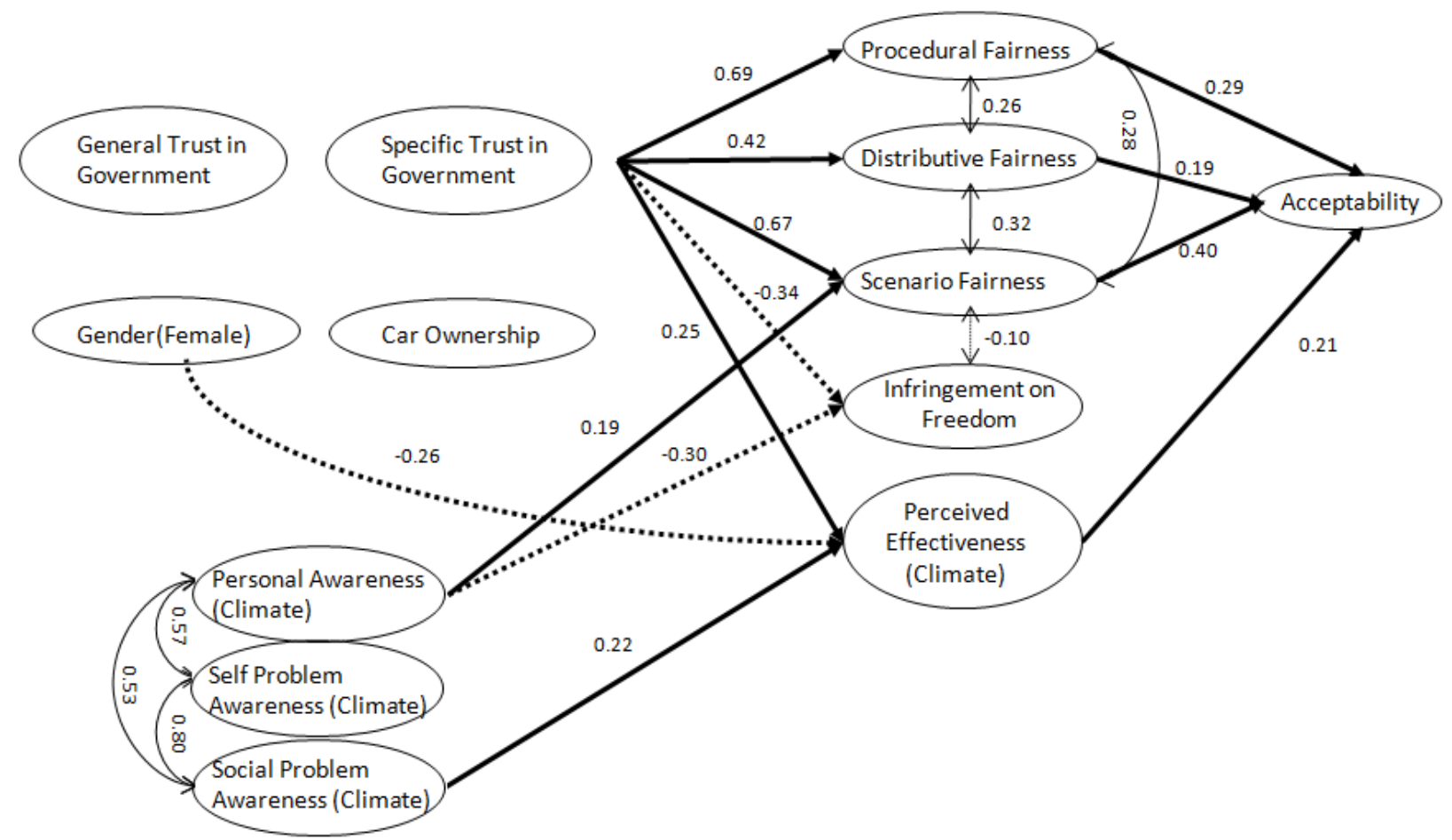

Figure 2. Results of the SEM analysis for road pricing in the U.S. sample $(n=93)$

(Ellipses represent latent variable; Thick left-to-right arrows represent paths significant at the $5 \%$ level; thin vertical two-way arrows represent significant correlations; dotted arrows represent significant negative paths or correlations).) 


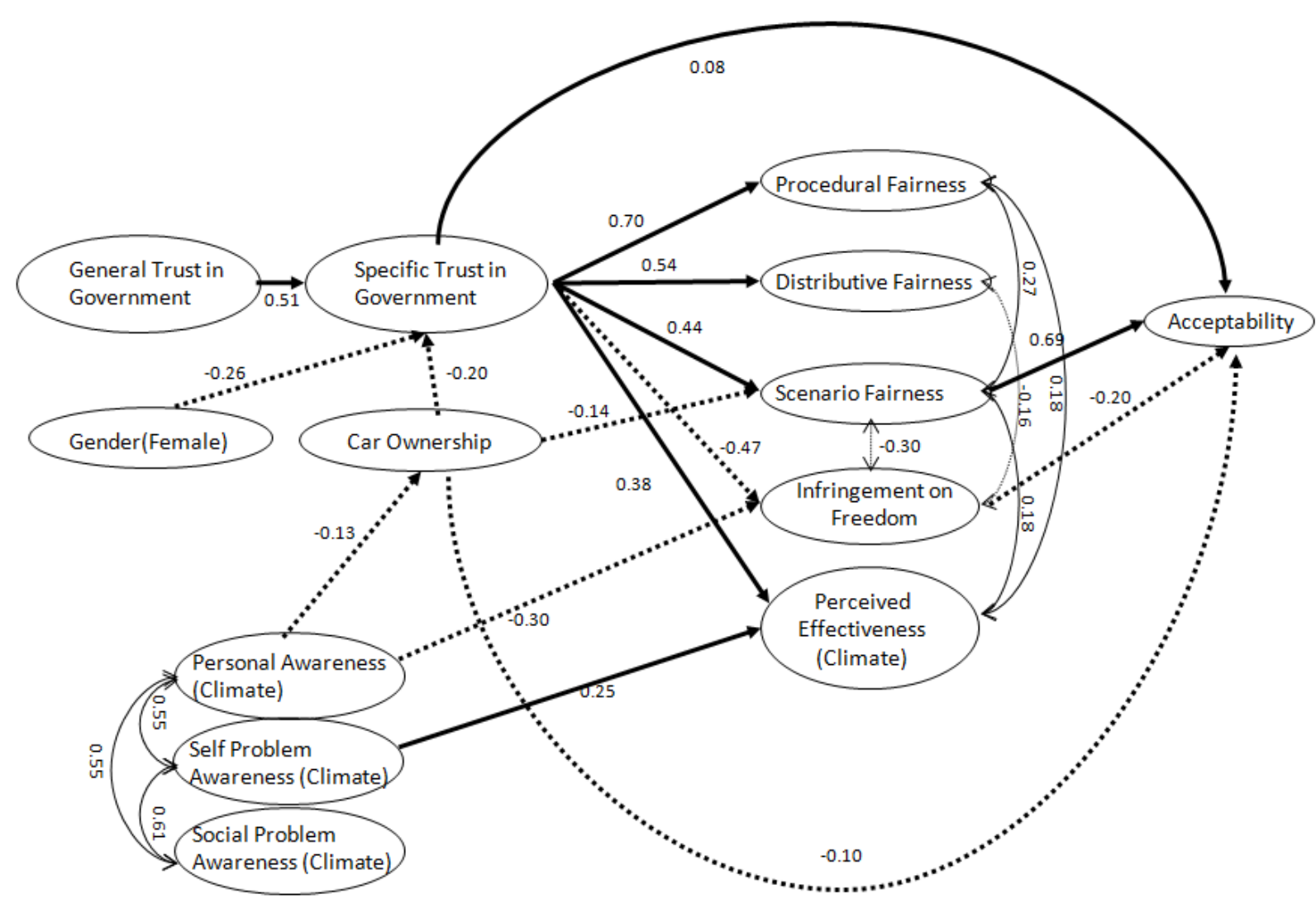

Figure 3. Results of the SEM Analysis for road pricing in the U.K. sample $(n=72)$

(Ellipses represent latent variable; Thick left-to-right arrows represent paths significant at the $5 \%$ level; thin vertical two-way arrows represent significant correlations; dotted arrows represent significant negative paths or correlations). 


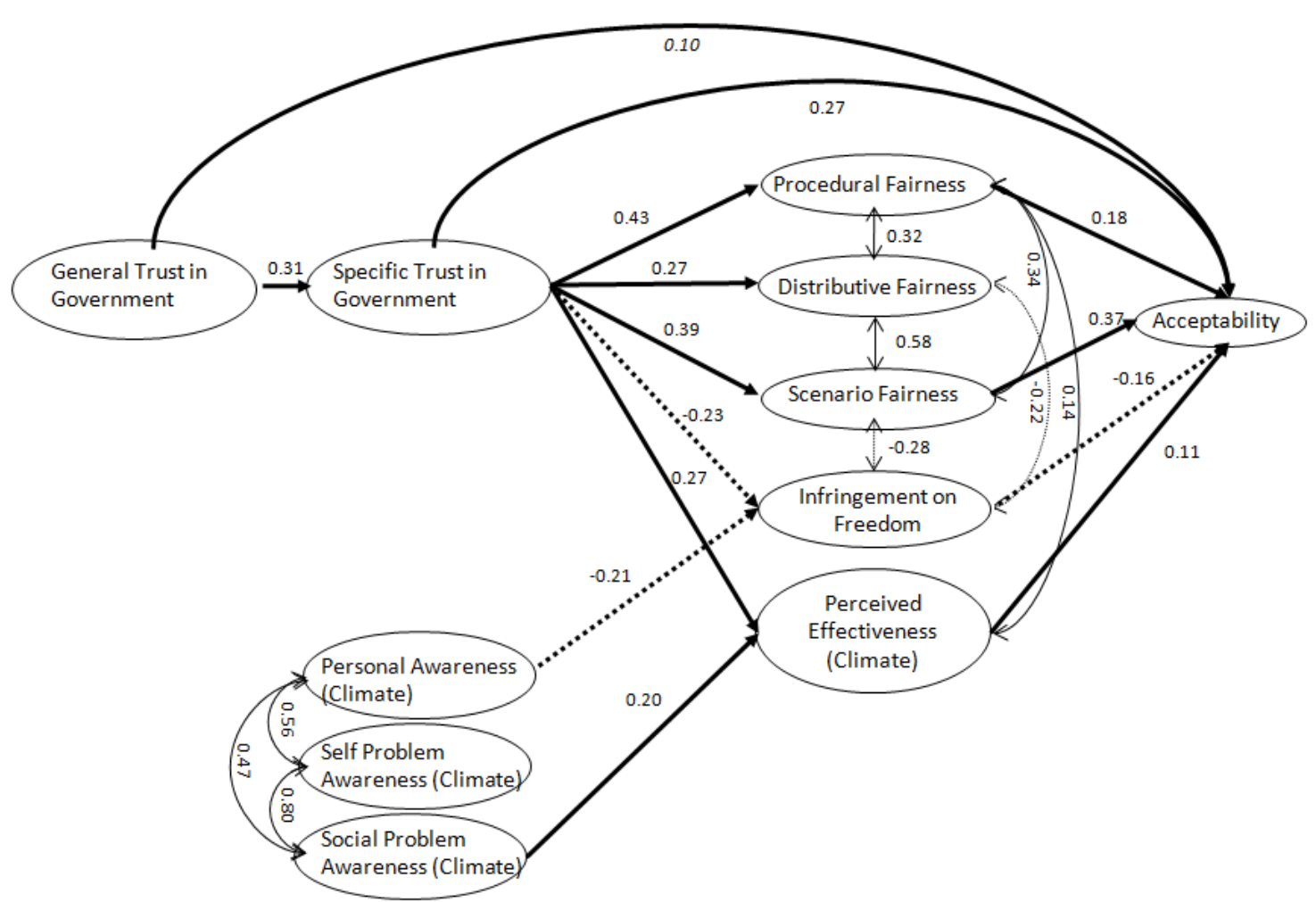

Figure 4. Results of the SEM Analysis for environmental taxation in the U.S. sample $(n=93)$

(Ellipses represent latent variable; Thick left-to-right arrows represent paths significant at the $5 \%$ level; thin vertical two-way arrows represent significant correlations; dotted arrows represent significant negative paths or correlations). 


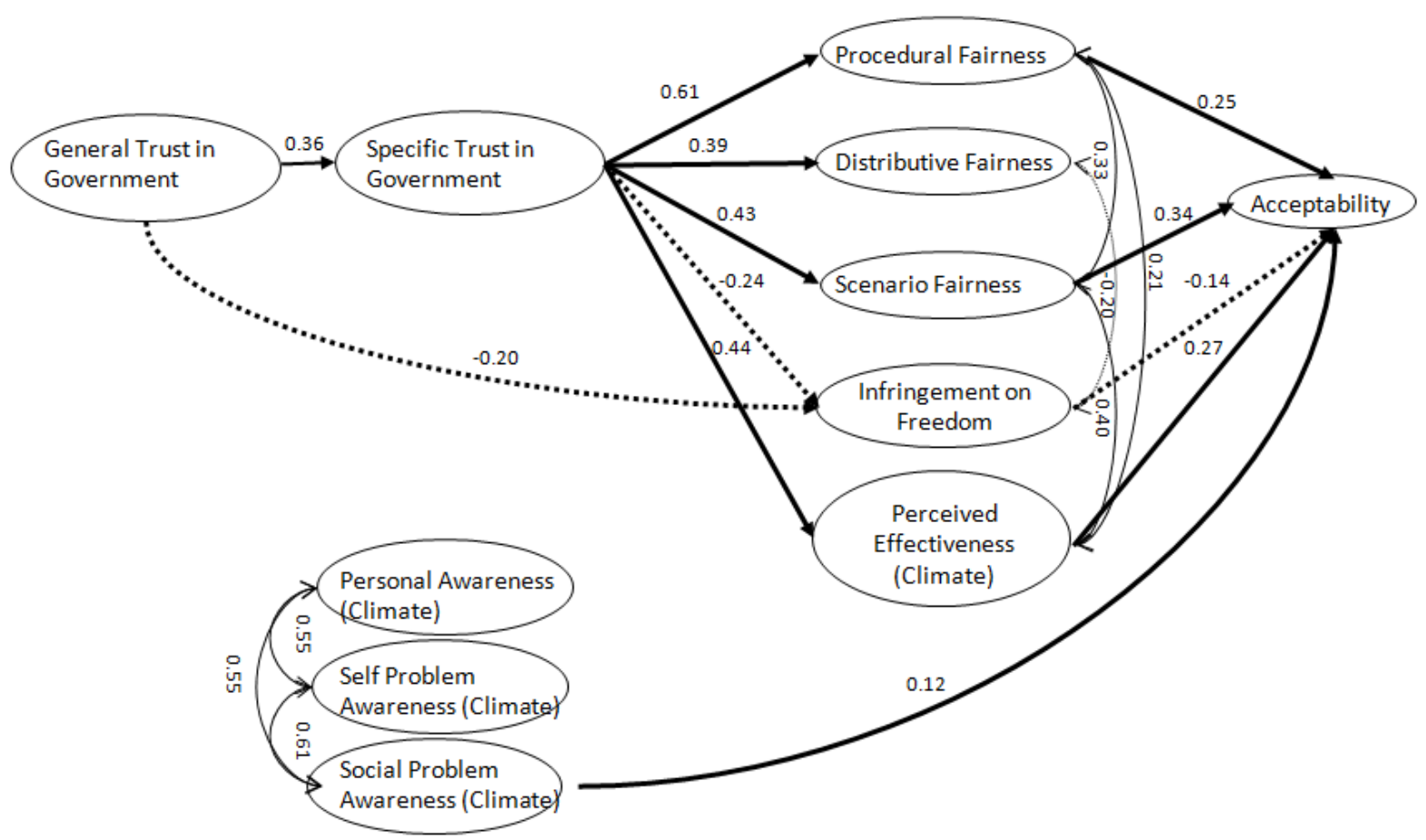

Figure 5. Results of the SEM Analysis of environmental taxation in the U.K. sample $(n=72)$

(Ellipses represent latent variable; Thick left-to-right arrows represent paths significant at the $5 \%$ level; thin vertical two-way arrows represent significant

correlations; dotted arrows represent significant negative paths or correlations). 